\title{
Computer Hardware Device
}

National Cancer Institute

\section{Source}

National Cancer Institute. Computer Hardware Device. NCI Thesaurus. Code C61402.

The physical components from which a computer is constructed (electronic circuits and input/output devices). 